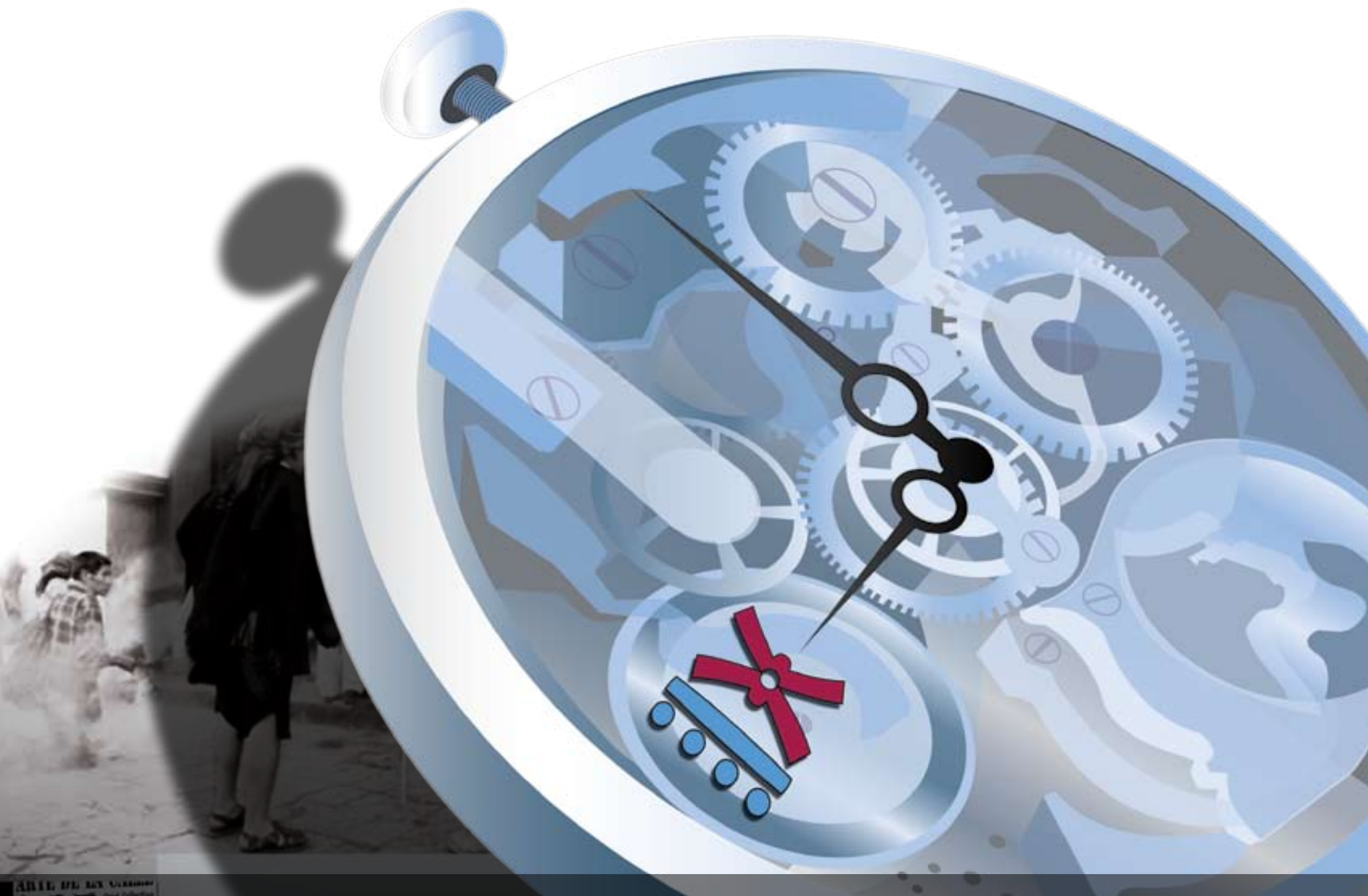

ᄀ9 $9^{\circ}$ CONGRESO ?2. CENTROAMERICANO DE HISTORIA
ISSN 1409-469X

Fecha de recepción: 15 de mayo 2008 Fecha de aceptación: 30 de mayo 2008

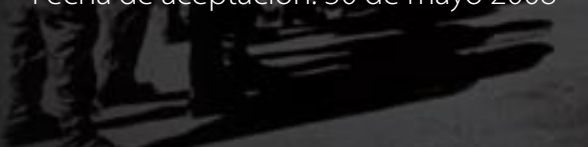

Apuntes sobre una crítica a la metodología investigativa Latinoamericana de la historia

Miembros del Consejo Editorial:

Dr. Ronny Viales, Dr. Juan José Marín

Editores Técnicos:

Allan Fonseca, Andrés Cruz, Gabriela Soto
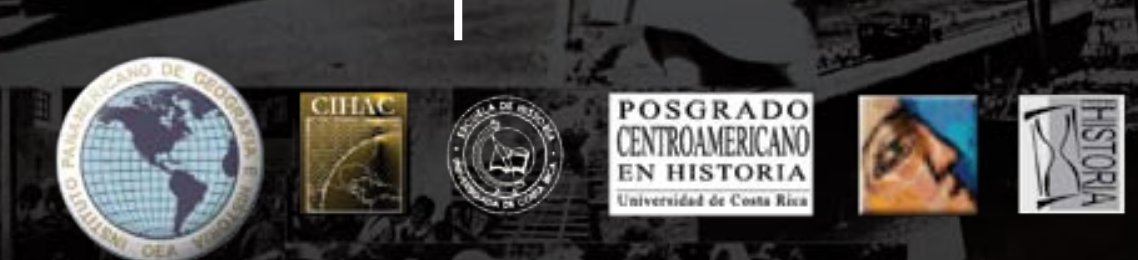
Indexaciones: Repositorio de Revistas UCR, DIALNET, Latindex, REDALYC Directorio y recolector de recursos digitales del Ministerio de Cultura de España, Directory of Open Access Journals. Diálogos Revista Electrónica de Historia ISSN 1409-469X. Número especial 2008. Dirección web: http://historia.fcs.ucr.ac.cr/dialogos.htm

\title{
Apuntes sobre una crítica a la metodología investigativa Latinoamericana de la historia
}

\author{
Fabio Andrés González \\ Juan David Alzate
}

Estudiantes de Historia Universidad de Antioquia. Coordinadores del Grupo de Estudio y Trabajo HICRIPO. Historia Crítica y Política. hicripo@gmail.com 
"Si la construcción del futuro y el resultado final de todo los tiempo no es asunto nuestro, es todavía más claro lo que debemos lograr en el presente: me refiero a la crítica despiadada de todo lo que existe, despiadada en el sentido de que la crítica no retrocede ante sus propios resultado ni teme entrar en conflicto con los poderes establecidos." Karl Marx

Hemos notado últimamente como se producen una serie de invitaciones, de hecho bastante particulares, a participar de coloquios, foros, seminarios y demás espacios, con la finalidad de llevar a cabo un concienzudo debate sobre los 200 años de la independencia latinoamericana.

Nos alegra saber que se estén planteando actualmente este tipo de debates, mas nos cuestiona el hecho de recaer en ese eterno retorno de seguir siendo nominales ante los procesos solo cuando están de moda. Verbo y gracia de ello, es lo que ocurrido para el 2001 en nuestro país, con la conmemoración de los 150 años de la abolición de la esclavitud, donde los más respetados academicistas escribieron profusos artículos y utilizaron toda clases de encuentros intelectuales para abordar la temática. Innegable los avances que se lograron, lastima que solo fuera tomada como la moda intelectual del momento, y que no alcanzara a generar un verdadero proceso de cambio dentro de la comunidad afro descendiente.

Sin el animo de hacerle el juego a la moda intelectual nos sumamos a la importancia del estudio serio, crítico y propositivo del fenómeno independentista latinoamericano, pero nos parece que deberíamos emprender ese largo trasegar del conocimiento partiendo del cuestionamiento ¿200 años de independencia?, ¿de qué independencia debemos hablamos? 
El diccionario de la Real Academia de la Lengua Española define a un eufemismo como la "manifestación suave o decorosa de ideas cuya recta y franca expresión sería dura o malsonante" y estamos seguros de no estar solos en el planteamiento que "la independencia" es un eufemismo. Pues en realidad deberíamos reconocer que más que independencia, entendida en la magnitud de su palabra como un proceso emancipatorio , lo que se dio fue una reorientación de los centros de poder hacía diferentes potencias.

Ha medida que hemos logrado una serie de estudios sobre la llamada independencia de España, vemos como surgen a la par una abundante bibliografía que muestra una Latinoamérica aun colonizada y subyugada a las grandes potencias que vienen con una nueva cruz bajo el brazo, el libre mercado. Donde no solo entra a mediar el sometimiento económico, político y militar, si no que se nota también la reproducción de un conocimiento colonizado.

Cuando hablamos de conocimiento colonizado nos referimos a esa constante necesidad "científica" de ver a Europa como el único y solamente el único lugar donde se produce el conocimiento. Negando así la apelación a la riqueza y diversidad de nuestros saberes populares, construidos a través del tiempo en diferentes lugares, y que deben establecerse en un dialogo de conocimientos que propendan por una compresión mas global de los problemas.

La pregunta entonces por la independencia de Latinoamérica nos lleva a preguntarnos el papel de la historia, quizás como lo enunciaba Duby de que "la función crítica de la historia me parece más urgente $[\ldots]$ la historia es ante todo el ejercicio de la libertad"1. El ejemplo de la independencia es 1 George Duby, "El ejercicio de la libertad”, Sociología (Colombia) 20 (Junio 1997): 15. 
poblados de 500 y 1.000 habitantes denominados "caletas" a orillas del mar. Dado que no cuentan con infraestructura básica en sus inicios, estos caseríos impactan el paisaje del entorno en forma significativa, recolectando los escasos frutos silvestres y hierbas nativas, leña permanente y acumulación de desechos producto de sus actividades productivas y domésticas. Se intensifica la pérdida de los renuevos nativos y la extracción de recursos del mar, siendo extinguidos al siglo 21, a tal punto que varias especies ictícolas se encuentran bajo régimen de "vedas" o cuotas, para asegurar el desarrollo sustentable de la fauna y flora autóctonas. Otro hecho significativo es que a partir del año 2000, el Estado de Chile ha propuesto subsidiar a las personas que planten bosque nativo, con el objetivo de incentivar la reforestación con especies autóctonas y a aquellos propietarios que mantengan el bosque in situ.

En los sectores desde Loanco a Reloca, se presentan dos actividades económicas de uso del espacio actual, la agricultura-ganadería y la pesca-marisqueo en el mismo orden de importancia; la primera es altamente beneficiosa para evitar el avance de las dunas y ayudar a formar suelos cada vez más orgánicos con los desechos de los mismos productos y la asociación de una ganadería bovina y ovina que pasta en las áreas interiores de los valles intermontanos costeros y en pendientes suaves de hasta $15^{\circ}$ entregando abono natural a los suelos logrando restituir parte del funcionamiento del sistema, con la formación de una capa orgánica de hasta $10 \mathrm{~cm}$. y una biodegradación de los elementos utilizados.

La actividad pesquera en cambio, es reciente y se realiza como una alternativa en el período de crecimiento y evolución de las siembras; es de subsistencia y autoconsumo, por tanto la extracción es mínima. Sólo a partir del año 2007, se ha generado una restaurante en Loanco, de amplia gastronomía de mariscos locales, siendo una novedad ya que el propietario es lugareño. Algunos caseríos de alejan del mar como son Pahuil y El Pajal, desarrollando un uso del espacio 
único: agricultura asociada a ganadería mayor, siendo importante el aprovechamiento del abono orgánico generado por los desechos de ambas actividades.; estas localidades viven actualmente de la lechería, venta de quesos, quesillos y agricultura de autoconsumo y venta en período estival de cereales y leguminosas.

En Chanco, el uso del espacio ha sido tradicionalmente el agrícola de trigo, porotos, lentejas y chícharos, tanto en la primera terraza marina que coincide con las arenas de dunas fosilizadas, como en las planicies de abrasión marina hacia el interior, hasta los 200 metros de altura.

La ganadería bovina -lechería y carne- se alterna con la agrícola siendo altamente favorable para la reconstitución de los suelos, porque utiliza los desechos de cosechas y de forraje como abono orgánico, observándose incluso montículos cubiertos con polietileno en invierno, para proceder a fertilizar las tierras en primavera. También el uso del espacio con una rotación mixta de cultivos: trigo, papas, lentejas variando la leguminosa con porotos y chícharos, ricos en nitrógeno, les ha asegurado un mejor rendimiento de sus tierras

Si bien es cierto que estos suelos han sido históricamente a largo e intenso uso, no se encuentran agotados, teniendo un rendimiento bastante aceptable por hectárea; sí que la falta de riego, es un problema para la agricultura, puesto que acá en la zona la agricultura es de secano o con agua obtenida de pozos profundos.

Esta comuna vio desaparecer la vegetación nativa de la vertiente occidental de la Cordillera de la Costa a comienzos del siglo 20, siendo la menos afectada en el uso del espacio respecto de las otras áreas del borde costero.

Una actividad reciente, de la década del 2000 es la incorporación comercial de la "frutilla", fruta que ha reemplazado en muchos predios a la agricultura tradicional, obteniendo hasta tres cortes al año; dado que tiene trabajo todfo el año, asegura la actividad laboral y un salario que ha 
tan solo uno de esos términos que hemos acuñado por el uso frecuente, convirtiéndolo en verdades incuestionables de los postulados históricos y que nos llevan, en un ejercicio casi inconsciente, a seguir sintiéndonos como colonias.

Nuestro léxico está permeado constantemente de referencias despectivas que han sido rebatidas por toda clase de trabajos de científicos y científicas sociales. El término "nuеvo mundo" está totalmente revaluado pues estaba cargado de connotación para los que apenas llegaban a América, pero no para quienes la había poblado hace cuarenta mil años. Quizás “descubrimiento” podamos llamar a ese suceso en el que dos culturas se trasmiten mutuamente lo que estaba "escondido" pero no a la invasión y el saqueo desatado a sangre y fuego.

Así pues, los historiadores e historiadoras nos hemos dedicado a escribir la historia de los vencedores. Y la pregunta que nos hacemos todos y todas, desde la niña o el impávido transeúnte hasta los padres de la historia, de ¿para qué la historia? La hemos abordado desde múltiples respuestas recogidas a lo largo de siglos: la historia como maestra de vida, ejemplo de generaciones venideras, lección del presente. Palabras distintas para decir siempre lo mismo. Pero que al final desconocen el verdadero papel de cambio de los historiadores y las historiadoras en las sociedades.

El griego Heródoto, padre la historia clásica, inicia su trabajo poniendo de presente el compromiso social del historiador e historiadora, que debía ser agente de la memoria colectiva: la publicación que Heródoto de Halicarnaso va a presentar de su historia se dirige principalmente a que no llegue a desvanecerse con el tiempo la memoria de los hechos públicos de los hombres, ni menos 
a oscurecer las grandes y maravillosas hazañas, así de los griegos como de los bárbaros ${ }^{2}$

El compromiso social al que se refiere Heródoto no ha variado mucho, y se complementa con la premisa que los historiadores y las historiadoras somos hijos de nuestro tiempo, es decir que debemos tener claro nuestro papel en la sociedad en que vivimos. Pero este compromiso no es un compromiso estático, inmóvil, que se refugia en el indiferentismo oportunista, el desilusionado conformismo, ni la complacencia resignada, como diría Bourdieu. ${ }^{3}$

Este llamado al compromiso social que hacemos de la historia, no debe estar centrado exclusivamente para dicha disciplina. Debe estar atendido por todas la ramas del conocimiento social como instancia crítica en lo formativo e investigativo. Tenemos los científicos y las científicas sociales un deber ético y una responsabilidad ante la sociedad que no nos permite refugiarnos en una torre de luz y sabiduría como lo es la academia, para eludir el debate de los problemas que esperan ser interpretados y resueltos. Allí, en el eclecticismo académico, evadimos nuestra responsabilidad escudándonos en la supuesta neutralidad o en la pasividad intelectual sospechosa.

Este compromiso, en el que hemos venido haciendo ahínco, no tiene un carácter mesiánico, en el que los científicos y las científicas sociales llegan cargados de soluciones y salvaciones a las condiciones de marginamiento y exclusión social, que son las características generales de Latinoamérica. El compromiso es acompañar desde la especificidad de su disciplina a esos sectores sociales relegados al olvido, acallados por la reproducción de un conocimiento excluyente, para 2 Heródoto de Halicarnaso, Los nueve libros de la historia. (Barcelona: Ed. Iberia, 1947), 10 3 Pierre Bourdieu y Loic Wacquant, Una invitación a la sociología reflexiva (Buenos aires, Argentina: Editorial Siglo XXI, 2005) 
que ellos mismos forjen una imagen identitaria, a que generen procesos de empoderamiento que lleven a una construcción de poder popular en su beneficio.

A la historia le corresponde una finalidad distinta del lujo cultural, de la acumulación de conocimiento, que hemos venido repitiendo y que solo se convierte en un dialogo entre eruditos, que no hacen más que llenar las vitrinas de las librerías y los auditorios para alabarse mutuamente por la genialidad de sus pomposos discursos.

“¿Cuántos estudios tenemos de élites políticas y su proceso de toma de decisiones, del funcionamiento de las burocracias, de los empresarios (no solamente como innovadores o modernizadores, sino como grupos de intereses políticos y económicos), de los inversionistas extranjeros en los países subdesarrollados,[...] o simplemente de los variados y múltiples aspectos de la represión (física, cultural, sicológica, económica) que los grupos dominante utilizan para mantener el statu quo?"4. La historia debe estar pensada como la necesidad social de las comunidades, los pueblos y las naciones para entender el sentido mismo de su existencia, para reconstruirse y reconocerse así mismos como historia y constructores de historia a la vez; como un propósito cultural vivo, anclado en la conciencia de los pueblos. Y de allí la necesidad de la memoria histórica, como saber colectivo y ante todo, social y subversor del orden existente

Queremos contribuir hoy al ejercicio continuo de replanteamiento de la disciplina histórica; no queriendo hacer un pretencioso trabajo intelectual, ni proponer metodologías investigativas porque de hecho no tenemos ninguna, es más, ningún historiador o historiadora procede como los 4 Rodolfo Stavenhagen , "Cómo descolonizar las ciencias sociales", en "La Investigación-Acción Participativa. Inicios Y Desarrollos.", Maria Cristina Salazar, (Bogotá, Colombia, editorial Tercer mundo 1997), 37 


\section{IX) conctuss

Indexaciones: Repositorio de Revistas UCR, DIALNET, Latindex, REDALYC Directorio y recolector de recursos digitales del Ministerio de Cultura de España, Directory of Open Access Journals. Diálogos Revista Electrónica de Historia ISSN 1409- 469X. Número especial 2008. Dirección web: http://historia.fcs.ucr.ac.cr/dialogos.htm

manuales de investigación dicen que procedemos. Por el contrario queremos plantear una serie de críticas al trabajo teórico y metodológico que hemos adoptado hasta ahora, replantearnos no sólo los temas, sino mirar "los temas viejos con nuevas metodologías". Sumándonos al planteamiento de Manuel Moreno Fraginalss , quien además habla del "profundo deseo insatisfecho de justicia histórica [y propone] un manifiesto a favor del compromiso cívico del historiador, un alegato contra todo academicismo, contra todas las formas de acomodación al orden establecido".

5 Manuel Moreno Fraginals, "La historia como arma", en "la historia como arma y otros ensayos", (Barcelona, España, editorial Critica, 1983), 11-23 